\title{
Reflections from the GP surgery at the turn of the year
}

Peter Toon

J R Soc Med 2005;98:193-194

This Christmas, as usual, The Sound of Music was on TV. 'How do you keep a wave upon the sand?' ask the nuns in this film, which celebrates its 40th anniversary this year. An apposite image for you, I suspect, dear reader in 2055, since a wave may be the first thought 2005 brings to mind - the great tsunami which devastated South Asia at the turn of the year.

General practice is like a series of waves which one cannot stop. Day after day, waves of illness beat on the shores of our consulting rooms, superficially alike yet every one unique. Perhaps I can best give you, fifty years hence, an image of general practice in this year of the tsunami by describing a few waves that have beaten on my shore this week.

Most of them were probably little different from those encountered by whoever provides primary care in your day (will it I wonder be a doctor, a nurse or a pharmacist, or some new hybrid of all these trainings?). For instance, we see waves of parents (mostly but not now exclusively mothers) worried about feverish infants. You may have eradicated some of the really serious illnesses (meningitis, febrile convulsions) which give us and the parents most worry - so hard to diagnose and so potentially catastrophic if missed. But I doubt you will have eradicated the multiple viral exposures that educate the immune system, and I'm sure you won't have eradicated parental anxiety - though nurses, videophones and the internet are already in my day starting to take over from GPs in allaying this.

Then there are the other common illnesses we deal with in primary care. Illnesses, like waves, tend to come in groups. Today was very much a musculoskeletal morning. I saw a young man with back pain, off work for three weeks having injured his lumbar spine doing some repairs around the house. Although MRI adds another dimension to visualization in this sort of problem, it is still very limitedand in the majority of cases what we can see makes no difference to what we can do, so we only request it in recalcitrant cases. I wonder what sort of scanners you will

Peter Toon MSc MRCGP, took an early interest in psychology, publishing on homelessness and the doctor-patient relationship. He was a general practitioner in east London for 18 years and at University College London he helped develop and run a web-based MSc in primary care. He has also travelled in Russia, Uzbekistan, Latvia and Croatia, advising on primary care, and directed a World Bank project in Macedonia. He now works in Canterbury.

49 Broad Street, Canterbury, Kent CT1 2LS, UK have, and whether the therapy will have moved on at all? Doctors in science fiction stories always have superb visualization and effective healing techniques: will you have these or will you, like us (and as doctors have done since Hippocrates), assist whilst the body heals itself?

Another patient with a musculoskeletal problem was a young woman with neck pain following a whiplash injury in a car crash almost a year ago. Not surprisingly it is not getting better: how could it when her compensation claim will take another year or two to settle? Oh for a fast, nonconfrontational system to deal with cases like this, so that people can get on with their lives.

Delay in hospital treatment is another thing that stops people getting on with their lives. This morning I saw a man in whom I diagnosed hypothyroidism six months ago. Fortunately I started him on treatment myself, and he is now euthyroid. But he is still waiting for his scan and the opinion of an endocrinologist on whether anything else needs to be done about his nodule, so his thyroid disease cannot become just part of everyday life. They have poured billions of extra pounds into the NHS in recent years, yet the organization of simple things like scans, laboratory tests and outpatient appointments seems to get harder.

In Canterbury we have two universities, so as usual I saw a few student-patients this morning. Some come in with trivial problems - they've never had to cope with a cold or gastroenteritis alone before, and if you give them a prescription they don't know what to do with it. But they have a lot of depression and anxiety too- exam pressures, maintaining their jobs at supermarkets or in bars, and often coming to terms with troubles from their childhood such as parental divorce. And of course, what with contraception and sexually transmitted infections as well as relationship traumas, their sex lives take up quite a lot of their timeand ours.

As always I had a couple of patients with depression for follow-up, and one new case. I see more than the average number of patients with depression: our local quality standards mean they have to be seen at least every two months, and unlike people with other chronic diseases their problems are too varied to delegate to nurses with evidence-based protocols.

We are rather concerned about quality standards just now. The new GP contract, introduced last April, requires 
us to demonstrate what we are doing in managing chronic disease and anticipatory care. We are quite well placed to do this, since we have been fully computerized for a couple of years. More significantly, our local quality assurance programme had considerable influence on the new contract, so we were doing most of it already. But even so it is a lot of work. Not only do we have to provide structured and evidence-based care and record that we have done it, as before; now we also have to be sure we use the right computer codes, because the searches are going to be done automatically. Big Brother really is watching us! This means lots of time recording entries in the new 'correct' way. I hope they have made the technology less intrusive by your time.

This extra work is balanced by no longer having to do any out-of-hours work. When I started general practice twenty years ago it was felt to be rather slack not to do your own night-calls, and since we were responsible for the care that was provided, finding someone you could feel confident in to take over was not easy. So for several years I carried a pager every other night. Fortunately calls were few and far between: patients hesitated to disturb someone they would have to face later in the consulting room. The only social activities it ruled out were films and plays (one is sure to be paged as soon as the performance starts) complex cooking (ditto) and drinking alcohol. The advent of rotas and then GP cooperatives meant that, about ten years ago, the low-grade annoyance of the pager was replaced for most of us by infrequent intense bouts of impersonal night work seeing people we didn't know. Also, the advent of skilled paramedics and better but more complex emergency treatments mean that the medical emergencies I managed at home in my earlier life-status asthmaticus, acute cardiac failure, even strokes and myocardial infarctions - are no longer part of general practice, except in remote areas. These big waves no longer hit us. So in one sense the change in responsibility for this service from GPs to the primary care trust had little obvious impact on us or on our patients. In the longer term, however, I wonder what will be the impact of the removal of first major then minor emergency care from general practice?

People think of Canterbury as prosperous - all clergymen and retired teachers. But there are quite a lot of poor people too, and the problems that go with that - unplanned teenage pregnancies, drug addiction, homelessness, sexual abuse and alcoholism. Their rather messy waves hit the surgery quite often. A young couple came in together. He is
18 , unemployed and covered in tattoos; she is 16 . They live with her parents, in one room. When she had her first unplanned baby last year they were both besotted, and despite social service concerns seemed to be caring parents, if slightly clueless. Now she is pregnant again and they can't cope, but they are not at all keen on an abortion. How will they manage? Will he succumb to petty crime, depression, addiction or suicide? What can one do? A friend of mine who has been a city magistrate for 20 years says he is now seeing the third generation of families from one of our worst estates in his courts.

I'm currently looking after a homeless man who gets the shakes if he goes without alcohol for more than five or six hours. He wants to stop, but the local alcohol service won't see him until he has stopped drinking for twentyfour hours. He can't do that and I'm unwilling to advise him to do so in case he gets delirium tremens. There are no facilities for inpatient detoxification. What am I to do?

And so they come in, wave after wave of human distress, discomfort, misery and despair. I've been in my present practice for 3 years now. We have to use an appointment system called 'advanced access' which only allows patients to book appointments on the day-perhaps better called 'impaired continuity', since it almost actively discourages patients from seeing the same doctor each time. Nevertheless, about half of my patients today I knew from previous consultations. This does help, especially when trying to deal with these intractable psychological problems, or sorting out elderly patients with multiple ills and complex drug regimens.

Most of the waves, the waves of patients' problems and the waves of political changes, wash round our feet. But occasionally there comes a large wave - almost a tsunami. I had one this morning, arranging a follow-up appointment for a young woman with a rare form of cancer. The consultant told me that the chances of her being alive in 2 years was $2 \%$. She is 23 and has two children under 5 . Just one person, against the many thousands killed in the Asian tsunami. But this wave knocked me off my feet. And despite all the technological advances, the gene therapies that no doubt you have, dear reader in 2055, I expect that you will from time to time encounter waves like that too, if you stand on the shore of human suffering that is clinical medicine.

Note The morning described here is imaginary, though based on clinical experience. Patient details have been changed to preserve confidentiality. 